\title{
PENYESUAIAN DIRI PADA MAHASISWA DISABILITAS
}

\author{
SELF-ADJUSTMENT IN STUDENTS WITH DISABILITIES
}

\author{
Oleh : \\ Robiana Rosydi ${ }^{1}$ \\ Dinar Sari Eka Dwi ${ }^{2}$
}

\begin{abstract}
This research aims to reveal the self-adjustment of disability students in Universitas Muhammadiyah Purwokerto. There are 6 informants involving 3 primary informants, disabled students who are actively studying, and 3 secondary informants who are the close friends of the primary informants. The research is qualitative research using a case study approach. The data were collected through interviews. The data credibility was checked through the triangulation method. The research result indicates that there are self-adjustment challenges in disability students, in the campus environment, are found. These challenges are in the form of establishing a new friendship, attitude, and behavior changes of every informant, changes in ways of thinking, and trying to be more independent. Moreover, obstacles in doing assignments and examinations are also found. In the campus environment, there are differences in establishing a friendship. These differences are in the form of friends' support, friend mutual relations, and trust. The same anxiety is also found, which is obtaining a bad score. In facing the problems, each informant said they share their problems with their trusted friends and try to overcome the problems in their own way.
\end{abstract}

Keywords: Self-adjustment; Students; Disability.

\begin{abstract}
ABSTRAK
Penelitian ini bertujuan untuk mengungkap bagaimana penyesuaian diri pada mahasiswa disabilitas di Universitas Muhammadiyah Purwokerto. Informan penelitian ini sejumlah 6 informan, 3 informan primer yang merupakan mahasiswa disabilitas yang masih aktif berkuliah dan 3 informan sekunder merupakan teman terdekat informan primer. Penelitian ini memakai metode penelitian kualitatif dengan pendekatan studi kasus. Pengumpulan data menggunakan metode wawancara. Kredibilitas data menggunakan metode triangulasi. Hasil penelitian ini, dalam penyesuaian diri mahasiswa disabilitas terdapat tantangan yang dihadapi pada lingkungan kampus seperti menjalin hubungan pertemanan baru, perubahan sikap dan perilaku dari setiap informan, adanya perubahan cara pandang, berusaha lebih mandiri. Terdapat kendala pada pengerjaan tugas dan ujian. Dalam lingkungan kampus terdapat perbedaan hubungan pertemanan yaitu mengenai dukungan teman, hubungan timbal-balik serta kepercayaan teman. Adanya kekhawatiran yang sama yaitu berhubungan buruknya nilai yang diperoleh. Dalam menghadapi masalah yang ditemui setiap informan menceritakan masalah yang dihadapinya pada teman yang dipercaya dan berusaha mengatasi dengan caranya masing-masing.
\end{abstract}

Kata kunci: Penyesuaian diri; Mahasiswa; Disabilitas.

\section{PENDAHULUAN}

Berawal dari kasus yang peneliti jumpai di lapangan bahwa masih sedikit kampus yang berbasis inklusi yang menjadi biasa menjadi pilihan penyandang disabilitas untuk

\footnotetext{
${ }^{1}$ Robiana Rosydi, Universitas Muhammadiyah Purwokerto, robianarosydi@gmail.com

${ }^{2}$ Dinar Sari Eka Dwi, Universitas Muhammadiyah Purwokerto, dinardewi3@ gmail.com
} 
berkuliah, kebanyakan dari mereka memilih untuk langsung berkerja dan Sekolah SLB pada umumnya mempersiapkan penyandang disabilitas agar siap kerja. Adapun sebagian kecil dari mereka yang berasal dari sekolah normal atau sekolah yang berbasis inklusi yang dapat melanjutkan ke perguruan tinggi. Penyandang disabilitas ketika akan mendaftar kuliah di jurusan yang mereka minati pun terkadang menemui adanya kriteria fisik yang mengakibatkan mereka tidak bisa mendaftar di jurusan yang mereka minati.

Belum tersedianya kampus inklusi di wilayah purwokerto membuat penyandang disabilitas jarang terlihat di area kampus. Kurangnya fasilitas yang mendukung bagi penyandang disabilitas pada lingkungan perkuliahan membuat mereka ruang gerak mereka yang terbatas dan kurang memadai bagi aktifitas mereka, adapun dikarenakan kurangnya rasa percaya diri dan faktor masalah ekonomi.

Dari data yang masuk ke Direktorat Pembelajaran Kemenristekdikti tercatat ada 401 mahasiswa disabilitas dari 152 perguruan tinggi yang telah melaporkan. Mereka berasal dari berbagai jenis hambatan (tunanetra, tunarungu, tunadaksa dan lain-lain) dan mereka tersebar di berbagai program studi. (Panduan Layanan Disabilitas Di Perguruan Tinggi, 2017).Menurut World Health Organization (WHO) difabel atau disabilitas adalah istilah yang meliputi gangguan, keterbatasan aktivitas, dan pembatasan partisipasi. Gangguan adalah sebuah masalah pada fungsi tubuh atau strukturnya; suatu pembatasan kegiatan adalah kesulitan yang dihadapi oleh individu dalam melaksanakan tugas atau tindakan, sedangkan pembatasan partisipasi merupakan masalah yang dialami oleh individu dalam keterlibatan dalam situasi kehidupan (World Health Organization, 2011). Penyandang disabilitas didefinisikan sebagai orang yang mengalami keterbatasan fisik, intelektual, mental, dan/atau sensoris dalam jangka waktu lama yang dalam berinteraksi dengan lingkungan dapat mengalami hambatan dan kesulitan untuk berpartisipasi secara penuh dan efektif dengan warga Negara lainya berdasarkan kesamaan hak (Undang-Undang Penyandang Disabilitas, 2016).

Menurut Sunarto dan Hatorno (2008) berpendapat bahwa individu mampu melakukan penyesuaian diri yang baik adalah individu yang tidak menunjukkan frustrasi pribadi dan menghargai pengalaman. Proses penyesuaian ini melibatkan penyesuaian untuk kehidupan Universitas, penyesuaian emosional mengenai penerimaan diri individu dan ketegasan berdasarkan persepsi diri, penyesuaian sosial meliputi komunikasi dengan teman, hubungan dengan lawan jenis dan akademik penyesuaian (Parmaksız, 2019).

Menurut Scheineders (1964) mengemukakan bahwa penyesuaian diri merupakan suatu proses mental dan tingkahlaku yang mendorong seseorang untuk menyesuaikan diri sesuai dengan keinginan yang berasal dalam diri sendiri, yang dapat diterima oleh lingkungannya. Penyesuaian diri menurut Scheineders (dalam Susanto, 2018) meliputi empat aspek yaitu: a) Adaptation. Individu dapat memuaskan tuntutan sosial, mempertakankan eksistensinya dan dapat memperoleh kesejahteraan rohani dan jasmani. b) Comformity. Penyesuaian diri sesuai dengan norma hati nurani diri sendiri dan norma sosial di masyarakat, membuat manusia bisa mencapai ketenangan dan kedamaian dalam hidup bermasyarakat. c) Mastery. Kontrol diri yang kuat dan kemampuan untuk merencanakan dan mengorganisasikan respons dalam cara-cara tertentu sehingga tidak terjadi konflik, kesulitan dan frustasi. d). Individual Variation. Masalah yang berhubungan dengan individualitas tidak boleh diabaikan. Menurut Schineider (dalam Susanto, 2018) bahwa penyesuaian diri yang baik di tandai dengan karakteristik sebagai berikut: a) Terhindar dari ekspresi emosi yang berlebihan, merugikan atau kurang mampu mengontrol diri. b) Terhindar dari mekanisme-mekanisme psikologis. c) Terhindar dari perasaan frustasi, kecewa karena sesuatu. d) Memiliki 
pertimbanggan dan pengarahan diri yang rasional. e) Mampu belajar untuk mengembangkan kualitas dirinya. f) Mampu memanfaatkan pengalaman masa lalu. g) Bersikap Objektif dan realistis sehingga mampu menerima kenyataan hidup yang dihadapi secara wajar.

Didasarkan pada hal tersebut peneliti melakukan studi pendahuluan yang dilakukan pada dua informan mahasiswa disabilitas. Informan pertama merasa kesadaran penggunaan aksesibilitas kurang, merasa mider dan kurang percaya diri, khawatir tidak bisa mendapatkan teman, susasana kampus baginya terasa individual. Informan kedua merasa aksesibilitas kurang memadai, membutuhkan waktu lama untuk menulis, merasa ragu ketika membahas orang lain, kesulitan mengolah kata untuk komunikasi. Berdasarkan studi pendahuluan masalah, hal ini membuat peneliti ingin meneliti mengenai "Penyesuaian diri pada mahasiswa disabilitas di Universitas Muhammadiyah Purwokerto".

\section{METODE}

Penelitian ini menggunakan metode penelitian kualitatif dengan pendekatan studi kasus. Pada penelitian ini akan berfokus pada bagaimana penyesuaian diri pada mahasiswa disabilitas di Universitas Muhammadiyah Purwokerto. Pengambilan subjek penelitian dengan cara purposive sampling Moleong (2013), peneliti mengambil 3 (tiga) mahasiswa sebagai informan primer, dan 3 (tiga) orang yang termasuk sahabat atau teman dekat. Adapun kriteria tersebut antara lain: 1) Informan Primer. Mahasiswa Universitas Muhamadiyah Purwokerto penyandang disabilitas fisik seperti anggota tubuh yang tidak lengkap karena bawaan lahir, kecelakaan, maupun akibat penyakit yang menyebabkan terganggunya mobilitas yang bersangkutan. 2) Informan Sekunder. Teman terdekat dengan informan primer seperti teman ataupun sahabat dikelas. Teknik pengumpulan data menggunakan teknik wawancara. Kredibilitas dalam penelitian ini dilakukan dengan teknik Triangulasi. Analisis data dalam penelitian ini menggunakan analisis data model interaktif (interactive model of analysis): 1) Pengumpulan Data. 2) Reduksi Data. 3) Penyajian Data. 4) Penarikan Kesimpulan.

\section{HASIL}

Hasil penelitian pengambilan data yang dilakukan pada 3 informan primer dan 3 informan sekunder terdapat informasi sebagai berikut:

1. Keberanian, berbuat baik dan membaur dengan lingkungan.

Dari ketiga informan $\mathrm{M}, \mathrm{HN}$ dan A menyampaikan terdapat tantangan yang dihadapi saat beradaptasi dilingkungan perkuliahan seperti menjalin hubungan pertemanan baru serta dibutukannya perubahan sikap, cara pandang saat bertemu oranglain dan berusaha lebih mandiri. Waktu yang dibutuhkan untuk terbiasa dengan lingkungan kampus pun bervariasi, ke tiga informan juga memiliki perbedaan cara pandang khususnya HN yang selalu mengutamakan kehati-hatian dalam berbicara kepada orang lain serta tidak mudah percaya dengan orang lain. A menyampaikan perlunya fasilitas yang bisa membantunya lebih leluasa untuk beraktifitas seperti lift untuk membantunya menaiki tangga dan ukuran toilet yang cukup untuk masuknya kursi roda, A memang memiliki kendala dalam menulis tetapi tidak mempengaruhi kemampuannya dalam mengerjakan UTS/UAS sehingga A meminta diketikan oleh petugas TU.

2. Menjalin hubungan perteman.

Dari ke tiga informan terdapat perbedaan kondisi dalam pertemanan yang ada dilingkungan kampus. M menyampaikan dirinya mudah dekat dengan siapa pun, pernah tidak akur dengan temannya, namun merasa kesal ketika temannya datang disaat membutukannya saja. Informan $\mathrm{HN}$ menyampaikan lebih hati-hati, ngobrol seperlunya atau jarang basa-basi, HN menyampaikan pernah renggang dengan temannya dikarenakan 
cara bicaranya yang blak-blakan seperti yang disampaikan MA. A menyampaikan tidak memiliki masalah dalam hubungan pertemanannya, menurut A dalam upayanya dalam membaur dengan temannya perlu membuat mereka nyaman dan membutuhkan

pikiran yang lebih terbuka, A menyampaikan memiliki teman yang bisa menerimanya dengan baik dan temanya senantiasa membantunya.

3. Kekhawatiran dan upaya mengatasi masalah.

Dari ketiga informan memiliki kekhawatiran yang sama yaitu berhubungan dengan buruknya nilai akademik yang diperoleh. Masalah akademik tidak terlalu menggangu dan dapat diatasi dengan baik, masalah dalam pertemanan lah yang sering muncul seperti yang disampaikan oleh informan M dan HN. Dari ketiga informan memiliki perbedaan dalam menghadapi masalah, $\mathrm{M}$ menyampaikan dirinya akan menceritakan masalah yang dialaminya namun tergantung pada moodnya terutama pada masalah pribadi yang benarbenar orang lain tidak boleh tau, dalam menyelesaikan masalah akan melihat pokok permasalahan, memberi nasihat kepada teman, memberi teguran. $\mathrm{M}$ disaat ada masalah dengan dirinya maka akan curhat ke teman SMA karena belum menemukan teman lebih dekat diperkuliahan. A menyampaikan setiap masalah ada solusi dan bisa dicari, adanya perbedaan dalam menyikapi masalah dengan dirinya yang dahulu khususnya lebih berpikiran terbuka.

4. Pandangan terhadap teman.

Dari ketiga informan, $\mathrm{M}$ dan A menyampaikan tidak ada perbedaan perlakuan dari teman-temannya dan tidak pernah mendapakan perlakuan buruk dari teman-temannya berkaitan dengan kondisi fisik mereka, $\mathrm{M}$ dan $\mathrm{A}$ menyampaikan dirinya terbuka kepada siapapun yang ingin berteman dengannya. HN menyampaikan pernah merasa dipandang dirinya aneh sebelumnya karena teman-temannya menjadi menjauhinya, HN juga memilih teman yang bisa menjaga perkataannya.

\section{DISKUSI}

Penyesuaian diri muncul karena adanya perbedaan dari lingkungan sebelumnya, mahasiswa disabilitas beradaptasi supaya dapat sesuai dengan lingkungan barunya agar tidak menimbulkan masalah selama menjalani aktifitas dilingkungannya. Mahasiswa disabilitas beradaptasi mulai dari dirinya sendiri dengan merubah sikap, cara pandang dan berusaha lebih mandiri dikampus. Mahasiswa disabilitas menjumpai banyak orang dengan berbagai macam sifat yang dimilikinya dan berupaya untuk mengenali serta menjalin hubungan pertemanan dengan orang lain. Informan primer ketiganya ketika akan masuk ke UMP memiliki kekhawatiran yang sama berkaitan dengan penerimaan kondisinya dilingkungan kampus.

Adapun temuan lain dalam penyesuaian diri yang mereka alami dipengaruhi dari bagaimana lingkungan sebelumnya diperlakukan. Mahasiswa disabilitas yang pernah mendapatkan pelakuan tidak mengenakan dari lingkungan sebelumnya memiliki kecenderungan lebih tertutup dan lebih berhati-hati dalam menjalin hubungan pertemanan baru dan sebaliknya bila dilingkungan sebelumnya memperlakukannya dengan baik mereka akan lebih terbuka kepada siapapun. Dalam hal ini sejalan dengan Fatimah (2006) mengatakan bahwa pengalaman yang menyenangkan atau pengalaman yang menyusahkan (traumatik) merupakan pengalaman yang berarti memiliki pengaruh terhadap penyesuaian diri seseorang.

Penyesuaian diri yang dihadapi mahasiswa disabilitas kerap menemui kendala salah satu informan mengeluhkan perlunya tambahan fasilitas untuk membantunya beraktifitas lebih mandiri mesikpun kedala tersebut bisa teratasi dengan bantuan orang lain. Dengan 
adanya fasilitas yang mendukung bagi mahasiswa disablititas akan lebih memudahkan mereka untuk beraktifitas lebih mandiri serta bisa leluasa mengakomodasi kebutuhan mereka perlukan. Dalam hal ini sejalan dengan Gunarsa (2008) bahwa penyesuaian diri yang baik adalah ketika seseorang dapat menunjukkan sikap yang ramah terhadap orang lain, ikut berpartisipasi dan dapat menjalankan perannya sebagai anggota di kelompoknya.

Dari ketiga informan, $\mathrm{HN}$ dan A memiliki kendala difungsi gerak yang dimilikinnya dan membuatnya mengalami kesulitan dalam menulis dan membutuhkan waktu lebih untuk mengerjakan tugas ataupun ujian. Keduanya memiliki cara memiliki caranya masing-masing, $\mathrm{HN}$ jauh-jauh hari akan terlebih dahulu diberi bagian tugas yang $\mathrm{HN}$ harus kerjakan seperti yang disampaikan MA, dalam menghadapi ujian $\mathrm{HN}$ akan terlebih dahulu mempelajari materi ujian agar dapat menyesuaikan waktu pengerjaan ujian dan A dalam mengerjakan ujian melalui lisan yang kemudian akan diketikan oleh petugas diprodinya, untuk itu diperlukannya modifikasi dalam pengerjaan tugas dan ujian untuk membantunya lebih mudah dalam pengerjaannya yang disesuaikan dengan kebutuhan mereka. Selain dari kendala-kendala yang berhubungan dengan fungsi gerak dalam hal akademik ketiga informan merasakan malas dan mengkhawatirkan nilai yang diperolehnya. Masalah akademik tidak terlalu menggangu, masalah dalam pertemanan lah yang kerap sekali dirasa informan. Sejalan dengan penelitian sebelumya yang dilakukan Sholeh (2015) mengungkap bahwa realitanya kesempatan dan fasilitas bagi penyandang disabilitas kurang mendapat perhatian dan kebijakan-kebijakan yang dikeluarkan di perguruan tinggi kurang senitif terhadap disabilitas.

Dalam hal hubungan pertemanan terdapat masalah yaitu mengenai dukungan pertemanan, kepercayaan terhadap teman, hubungan timbal balik yang berkaitan dengan kebergantungan teman dalam hal-hal tertentu. Masalah pertemanan muncul karena perbedaan dalam cara pandang atau menyikapi orang lain yang dimiliki sebelumnya. Mengenai kondisi fisik hampir ketiga informan tidak mempermasalahakan kondisi yang dimilikinya namun salah satu informan pernah dipandang sebelah mata karena gaya bicara dan performa yang dimilikinya. Disaat menemui masalah atau kendala informan berusaha menceritakan masalahnya pada orang yang benar-benar dapat dipercaya ataupun berusaha menyelesaikan langsung pada inti masalahnya. Sejalan dengan Fajria (2018) mengungkapkan bahwa tekanan yang dihadapi mahasiswa antara lain berupa masalah keuangan, beban tugas, ujian dan masalah interaksi dengan temannya.

\section{KESIMPULAN}

Kesimpulan dari penelitian ini, bahwa penyesuaian diri mahasiswa disabilitas terdapat tantangan yang dihadapi ketika beradaptasi dilingkungan kampus seperti menjalin hubungan pertemanan baru, adanya perubahan sikap dan adanya perubahan cara pandang sewaktu menghadapi dalam oranglain, berusaha lebih mandiri. Mengenai hal akademik tidak terlalu memberikan masalah nampun tetap diperlukan modifikasi dalam pengerjaan ujian. Dalam pernyesuaian diri mahasiswa disabilitas pada lingkungan kampus terdapat perbedaan kondisi yang berkaitan dengan hubungan pertemanan yaitu mengenai dukungan teman, hubungan timbal-balik serta kepercayaan teman disekitarnya. Terdapat kekhawatiran yang sama yaitu berhubungan dengan akademiknya misalnya buruknya nilai yang diperoleh. Dalam menghadapi masalah menceritakan masalah yang dihadapinya pada teman yang dipercaya dan berusaha mengatasi dengan caranya masing-masing. 


\section{SARAN}

Berikut ini saran yang dapat diberikan oleh peneliti kepada lingkungan sekitar dan teman-temannya diharapkan selalu memberi dukungan, saran dan bantuan kepada mahasiswa disabilitas membutuhkan bantuan. universitas diharapakan bisa memfasilitasi mahasiswa disabilitas. Kepada peneliti selanjutnya agar dapat melakukan penelitian lebih mendalam mengenai penyesuaian diri pada mahasiswa disabilitas.

\section{KEPUSTAKAAN}

Fajria, A. R. (2018). Hubungan Antara Spiritualitas Dengan Resiliensi Pada Mahasiswa Bidikmisi Angkatan 2014 Fakultas Ilmu Pendidikan Universitas Negeri Yogyakatra. Jurnal Riset Mahasiswa Bimbingan dan Konseling, 4 (8), 396-406.

Fatimah, Enung. (2006). Psikologi Perkembangan: Perkembangan Peserta Didik. Bandung: CV PUSTAKA SETIA.

Gunarsa, S. D. (2008). Perkembangan Anak dan Remaja. Jakarta: Gunung Mulia.

Moleong, L. J. (2013). Metodologi Penelitian Kualitatif. Bandung: PT. Remaja Rosdakarya.

Panduan Layanan Disabilitas Di Perguruan Tinggi. (2017). Ristckdikti.

Parmaksiz , İ. (2019). Assertiveness as the Predictor of Adjustment to University Life amongst University Students . International Journal of Instruction, 12 (4).

Schneiders. (1964). Personal Adjusment and Mental Health. New York: Holt, Rinehart and Winston

Sholeh, A. (2015). Islam dan Penyandang Disabilitas: Telaah Hak Aksesibilitas Penyandang Disabilitas dalam Sistem Pendidikan di Indonesia. Palastren, 8 (2)

Sunarto, dan Hartono, A. (2008). Perkembangan peserta didik. Jakarta: Rineka Cipta.

Susanto, A. (2018). Bimbingan dan Konseling di Sekolah. Jakarta: Prenadamedia Group.

Republik Indonesia. 2016. Undang-Undang No. 8 Tahun 2016 tentang Penyandang Disabilitas. Sekretariat Negara. Jakarta.

World Health Organization. (2011). Disabilities. Diakses 23 Desember 2019, dari https://www.who.int/topics/disabilities/en/ 